This PDF is a selection from an out-of-print volume from the National Bureau of Economic Research

Volume Title: New Developments in Productivity Analysis

Volume Author/Editor: Charles R. Hulten, Edwin R. Dean and Michael J. Harper, editors

Volume Publisher: University of Chicago Press

Volume ISBN: 0-226-36062-8

Volume URL: http://www.nber.org/books/hult01-1

Publication Date: January 2001

Chapter Title: A Perspective on What We Know About the Sources of Productivity Growth

Chapter Author: Zvi Griliches

Chapter URL: http://www.nber.org/chapters/c10136

Chapter pages in book: (p. $609-612)$ 


\title{
A Perspective on What We Know About the Sources of Productivity Growth
}

\author{
Zvi Griliches
}

In the little time that I have I would like first to remember three people who have died recently and who were important in the development of our topic and also in my life. The most recent to die was Ted Schultz, my teacher and mentor. Ted was the first to make quantitative estimates of the role of $R \& D$ and of education in accounting for the "unexplained" growth in output. He opened the way for Gary Becker, myself, and others. Ed Mansfield took technological change seriously and did his own thing, careful studies at the micro level, and he enriched this field immensely. Several years have already passed, but we should also mourn the passing of Ed Denison, one of the pioneers of national accounting and one of the first to parse quantitatively the residual into its components. Even though we often disagreed on particular measurement issues, we all learned a lot from him. They will be missed.

More than 30 years ago, Dale Jorgenson and I looked at data on productivity and saw the challenge in the then unmeasured education and $R \& D$ contributions. In our paper we "explained" it all away by correcting for various measurement errors in capital and labor input. By the time Denison corrected some of our overreaching, a significant amount of "unknown" territory was still left to explain.

However, if you look at more recent productivity data, it is possible to claim that we have won! The explanation is now complete. All of the growth is being accounted for by the growth in relevant inputs. Yet, in

Zvi Griliches passed away on 4 November 1999. Prior to his death, he had been the Paul M. Warburg Professor of Economics at Harvard University and director of the Productivity and Technical Change program at the National Bureau of Economic Research. He was past president of the Econometric Society and of the American Economic Association and a member of the National Academy of Sciences. 
another sense, this "victory" is rather sad. The operation was successful but the patient died. What happened was that the unexplained part disappeared, not that the explained part of the growth increased.

I have three points to make. The first is that the current accounting framework is incomplete. (This is also the message of Dale Jorgenson's paper at this conference.) There are a number of productivity enhancing activities that use resources and maintain and improve our human capital but are not included in our official notions of national output. I have in mind here general education, specific training, health investments, and R\&D. There have been notable efforts to calculate the accumulation of national human capital as produced by the education system, from Ted Schultz's early efforts to the more recent extensive contributions by Jorgenson and Barbara Fraumeni. A convincing construction of the nation's health capital is still ahead of us, though initial progress has been made by David Cutler and his coauthors. Estimates of R\&D capital have also been produced, but the factual basis for the assumed "depreciation" and "spillover" rates is still rather thin. Yet, as we extend our notion of inputs to include other "capitals," we will also have to extend our notion of output and include the investments in such capital within it. At that point, they will become just like other "produced" inputs within the economic system and will stop being a "source" of growth in multifactor productivity (MFP), in the residual. Unless some of these investments earn social returns that exceed their private costs, they will contribute only to capital deepening, but not to longer term sustained growth in per capita consumption possibilities. For the latter, something must keep the long run rates of return to such investments from falling.

The second point is that longer term productivity growth comes from the discovery of new resources, new methods of doing things, and the exploitation of investment opportunities that such discoveries create. That's what Ted Schultz taught us. He, in turn, built on the ideas of Frank Knight, who was one of the first to claim that new knowledge keeps the long run return to all investment from falling. But new knowledge does not arrive in a steady continuing stream, or as manna from heaven. It does take resources, effort, and serendipity to search, find, and recognize it. It is a badly understood process, with random, but often clustered, outcomes which then create new opportunities for investment and allow the economy to approach a new equilibrium growth rate. Longer term growth in per capita consumption comes from a collection of such traverses, from lurching from one equilibrium to another. But from where do these above average return investment opportunities come? They come from the creation of new knowledge in science, in industrial R\&D labs, and from tinkering. They also come from the diffusion of knowledge and technology and from the elimination of various legal and social barriers to efficiency. It is during 
such traverses to new equilibria that some individuals and the society as a whole earn above average returns on their investments. And it is this area, where Ed Mansfield worked, that is underemphasized in the program of this conference and deserves more attention from us all.

The third point is that in the 1960s, we were struggling with the large unexplained residual. Most of the observed growth was not accounted for by the then-standard input measures. In the last twenty or more years, most of the residual has disappeared. We have had our famous productivity slowdown. Various attempts to explain why measured productivity growth fell, including my own, have not been very successful. Measurement error stories are plausible but seem unlikely to be of great enough magnitude to account for it all. I think that it is time that we turn our searchlights at least partially around from the recent data to the data from the 1950 s and 1960s. Are we really sure that we had all that growth in MFP then? If we don't know how to measure productivity growth in the service sectors, and hence we do not even expect substantive growth to show up there, why was measured productivity growing there then but not now? What did the Bureau of Labor Statistics know then that it has forgotten now? Or was the productivity growth real? If so, how and why did it change so much over time?

It is easy to make a long laundry list of desired measurement improvements. The measurement of high-tech output is still in its infancy, though this infant is graying perceptibly. It took twenty years to get us to a reasonable computer price index. It took another ten years to do the same for semiconductors. Large areas still need better measurement, including more mundane industries such as construction. We need a census of capital equipment. Our assumptions about the length of life and economic depreciation rates are based on pitiful scraps of outdated data. The upheavals of the recent decades, the downsizing of companies, the closing of plants, and the outsourcing of many activities must have led to significant abandonments of real capital in the various industries. However, most of it is still on our books, as far as productivity measurement is concerned. We need more data on actual hours worked by people, not just hours paid for, and on machine hours and the changing length of the business workweek. The utilization issue, raised in our original 1967 paper, has not really gone away, as can be seen from the Basu and Fernald paper in this conference. The data situation now is not much better than it was then, either.

The most difficult measurement area concerns the production and dissemination of information and new knowledge. The difficulty comes from the intangible nature of knowledge itself. It spreads without leaving many traces in the sands of the data. How are we to measure and evaluate our investments in science and in economics itself? Almost all of the production of science (as is also the case for other public goods) escapes our 
current measurement techniques, and it is not even on the agenda of the major statistical agencies. Yet, that is where the future answers to our old questions are likely to come from.

Thus, while I conclude that the glass is still half empty, this should not be taken as reason to despair. Rather, it is a challenge for the next generation of researchers to make progress. There is still a long way to go, but the previous generation has provided them with good shoulders on which to stand. 